\title{
Operation of a diesel engine with intake manifold alcohol injection
}

\author{
A. Damyanov ${ }^{1}$ (1) P. Hofmann ${ }^{1}$
}

Received: 18 January 2019 / Accepted: 19 February 2019 / Published online: 27 February 2019

(c) The Author(s) 2019

\begin{abstract}
The usage of ethanol and two different mixtures of ethanol and gasoline (E85 and E65) was investigated on a modified diesel engine designed to work in a dual-fuel combustion mode with intake manifold alcohol injection. The tests were conducted at five operating points covering low, medium and high load and different engine speeds. Additionally, an engine-process simulation model was built for the test engine and selected operating points from the engine test bed measurements were analysed with it. The discussion of the simulation results allows an efficiency analysis and therefore a better understanding of the findings of the engine test stand experiments. With rising alcohol amount, a significant reduction of soot mass and particle count was observed at all operating points. At some load conditions, substituting diesel with ethanol, E65 or E85 led to a reduction of the NOx emissions; however, the real benefit concerning the nitrogen oxides was introduced by the mitigation of the soot-NOx trade-off. The indicated engine efficiency in dual-fuel mode showed an extended tolerance against high EGR rates. It was significantly improved with enhanced substitution ratios at high loads, whereas it dropped at low loads. Substituting diesel with manifold injected alcoholic fuels impressively reduced the engine $\mathrm{CO}_{2}$ emissions at medium and high load operating points. Degrading combustion quality, irregular combustion phenomena and poor process controllability at low load and knock as well as auto-ignition at high load limited the maximum ethanol energy share to approximately $70 \%$ and $30 \%$, respectively.
\end{abstract}

Keywords Diesel engine $\cdot$ Dual fuel $\cdot$ Ethanol $\cdot$ Alcoholic fuel

\begin{tabular}{|c|c|}
\hline \multicolumn{2}{|c|}{ Abbreviations } \\
\hline EtOH & Ethanol \\
\hline E85 & $\begin{array}{l}\text { Mixture of } 85 \text { vol } \% \text { ethanol and } 15 \text { vol } \% \\
\text { gasoline }\end{array}$ \\
\hline E65 & $\begin{array}{l}\text { Mixture of } 65 \text { vol } \% \text { ethanol and } 35 \text { vol } \% \\
\text { gasoline }\end{array}$ \\
\hline CEC & Certified test diesel fuel \\
\hline OP & Operating point \\
\hline EGR & Exhaust gas recirculation \\
\hline MFB & Mass fraction burned \\
\hline CAaTDC & Crank angle after top dead center \\
\hline$c_{\mathrm{p}}$ & Specific heat capacity at constant pressure \\
\hline & Specific heat capacity at constant volume \\
\hline
\end{tabular}

A. Damyanov

aleksandar.damyanov@ifa.tuwien.ac.at

P. Hofmann

peter.hofmann@ifa.tuwien.ac.at

1 Institute for Powertrains and Automotive Technology,

Vienna University of Technology, Vienna, Austria

\section{Introduction}

The transport sector is a major contributor to the greenhouse gas emissions in the European Union with a share of about $24 \%$ in 2016 [1]. Reducing $\mathrm{CO}_{2}$ from traffic is crucial for achieving the desired climate stabilizing objectives and lowering the dependence on fossil fuels. The efforts on this field should be supported by rational as well as technically and economically feasible sustainable solutions. Increasing the usage of biofuels is one of these solutions [2]. Ethanol, in particular, is a very well-known fuel produced from different sources and by various methods [2-4]. Currently, new production processes are being used and developed to obtain a so-called second-generation biofuel from wastes and residuals mitigating the issues surrounding the competition to food production $[5,6]$.

Despite the present alternative powertrain development, the diesel engine is predicted to remain crucial for mobility of people and goods in the long term due to its unmatched efficiency, robustness and operation cost and flexibility. Therefore, the search for diesel substitute fuels that are sustainable and of wide availability is of high priority. The 
usage of ethanol is normally assumed with spark ignition engines, but not with a compression ignition engine, because of the very low cetane number of this fuel. However, there are several different possibilities to utilize this alcohol in a diesel engine and it is expected to defuse the classical soot-NOx trade-off due to its high oxygen content, advantageous molecule structure and better mixture formation and combustion process. Ethanol can be used as a single fuel in a dedicated ethanol compression ignition engine with a higher compression ratio. Such engines are available in the market. To ensure ethanol ignition, however, fuel additives are necessary [7]. Adding the alcohol to the conventional diesel fuel in the form of a so-called "blend" is another way of using it in a diesel engine. Though it is the simplest method, the ethanol quantity is very limited due to separation issues, poor ignitibility and current diesel norm EN590 violation in terms of cetane number and flash point [8]. Perhaps, the most promising technique for ethanol usage in a diesel engine is the unconventional application in the form of a dual-fuel combustion process. In this case, the alcoholic fuel is fed into the engine as a separate fuel and diesel is directly injected into the combustion chamber. The ignition of the diesel fuel starts the combustion of the alcohol-air mixture. This approach provides high substitution ratios and flexible operation based on the fuel availability — diesel only or dual fuel.

The dual-fuel combustion process itself is not a novelty, it has been used in certain applications since the very early age of the internal combustion engine with different fuels, mostly natural gas $[9,10]$, but also liquefied petroleum gas [9], gasoline [11], hydrogen [9], reformed gases [12, 13] and other alternative fuels [14]. It was in 1901 that Rudolf Diesel obtained a US patent covering the concept of the dual-fuel engine [15]. Similarly to the other low reactivity fuels mentioned, alcohols like ethanol or methanol $[8,16,17]$ can also be very successfully utilized in a dual-fuel-designed diesel engine. There are several possibilities to configure the dual-fuel system depending on the mixture formation method-external or internal. On the one hand, the alternative fuel can be added to the intake air upstream via manifold injection [18], carburettor or evaporator - a method widely known as "fumigation". On the other hand, the fuel may be directly injected into the combustion chamber through a dedicated injector [19] or a special dual-fuel injector for diesel and alternative fuel.

This study handles the operation of a diesel engine in a dual-fuel mode with an intake manifold ethanol injection. Several researchers have published articles on investigations of the dual-fuel combustion process with alcohols. The findings, however, are not always consistent and differ at some points, as can be concluded from a comprehensive review of many publications on this topic in [20]. It is believed that the discrepancies in the results found in literature have their origin in the differences of the used test engines, investigated load points, operating conditions and ethanol/diesel ratios. To obtain a wider perspective on the potentials and limits of the ethanol-diesel dual-fuel operation, in this study several important parameters were varied in wide ranges at five different operating points on a modern common rail diesel engine. Since the market availability of the gasoline-ethanol mixtures is higher, E85 and E65 were also tested parallel to pure ethanol. The literature review did not offer satisfactory explanations for the observed efficiency changes with rising amount of intake manifold alcohol injection; therefore, an engine-process model for the test engine was generated and selected operating points from the engine experiments were implemented. The conducted efficiency loss analysis supports the understanding of the measured results.

This article does not describe the potential $\mathrm{CO}_{2}$ savings, which would result by the usage of renewable ethanol, but only deals with the engine-related aspects. If, however, bioethanol is used, the holistic $\mathrm{CO}_{2}$ savings would be significantly higher. Bioethanol by the Austrian ethanol producer AGRANA, for instance, delivers certified GHG-savings of approximately $70 \%$ compared to fossil diesel fuel.

\section{Investigated fuels}

In this study, a certified CEC test diesel fuel was used as a reference for comparison. Technically pure ethanol was the first representative of the investigated oxygenated fuels. However, the intake manifold injected fuel does not necessarily have to be of high purity - a great advantage lies in the possibility of using lower-grade ethanol, since even higher water contents had no harmful impact on the engine. Additionally, E65 and E85 gasoline-ethanol mixtures were supplied, because their availability at filling stations is more presumable. E85 (RF-01-08) was delivered by a supplier and E65 was self-mixed (35 vol\% winter quality gasoline RF-04-03). Table 1 gives an overview of some of the tested fuel properties.

\section{Test engine and test methodology}

\subsection{Test engine and measurement equipment}

A modern inline four-cylinder diesel engine was modified for single-cylinder operation and used as a test engine. Only the first cylinder was fired, while the other three were deactivated and their gas exchange was separated from the gas exchange of the fired cylinder. The cylinder had a displacement of $537 \mathrm{~cm}^{3}$ and a compression ratio of 17.5 . Bore and stroke were 88 and $88.34 \mathrm{~mm}$, respectively. The original high-pressure common rail diesel injection system 
Table 1 Properties of the investigated fuels

\begin{tabular}{lllll}
\hline Fuel notation & Diesel & EtOH & E85 & E65 \\
\hline Ethanol/gasoline ratio [vol\%/vol\%] & - & $100 / 0$ & $85 / 15$ & $65 / 35$ \\
Density [kg/m ${ }^{3}$ ] & 831 & 789 & 782 & 773 \\
Lower heating value [MJ/kg] & 42.68 & 26.68 & 29 & 31.46 \\
Cetane number [-] & 54 & 8 & - & - \\
Research octane number [-] & - & 111 & 105 & 101 \\
C-fraction [wt\%] & 85.4 & 51.5 & 56.5 & 62.8 \\
H-fraction [wt\%] & 14.2 & 13.7 & 12.8 & 13.8 \\
O-fraction [wt\%] & 0.4 & 34.1 & 29.8 & 23.3 \\
H/C atomic ratio [-] & 1.99 & 3.2 & 2.72 & 2.65 \\
O/C atomic ratio [-] & 0.004 & 0.5 & 0.4 & 0.28 \\
$\mathrm{gCO}_{2}$ /MJ & 73.3 & 71.22 & 72.02 & 73.12 \\
$\mathrm{gH}_{2} \mathrm{O} / \mathrm{MJ}$ & 29.94 & 46.54 & 40.08 & 39.69 \\
\hline
\end{tabular}

was equipped with seven-hole nozzle solenoid injectors and could handle a pressure of up to 2000 bar. Charging was performed with an external electrically driven supercharger. An electrically adjustable flap valve was used to adjust a turbocharger comparable exhaust gas back pressure. Cooled high-pressure exhaust gas recirculation was applied. The standard exhaust gas aftertreatment system was removed and emission sampling took place in the raw exhaust gas. The temperatures of the charge air and the fuel were conditioned.

The alcoholic fuel was injected with a pressure of $4.5 \mathrm{bar}$ (abs.) into the intake air through a conventional gasoline injector, which was installed in a specially designed intake manifold.

The test engine was equipped with high- and low-pressure indication and standard exhaust gas measurement, as well as AVL Micro Soot Sensor 483 and AVL Particle Counter 489. Additionally, an AVL Smoke Meter 415S was used.

\subsection{Test methodology}

The investigations were conducted at five operating points, which cover a typical commercial vehicle engine operating map. The engine load varied between 5 and 20 bar indicated mean effective pressure (IMEP) and the speed was between 1500 and $3000 \mathrm{rpm}$. The most important engine operating parameters are depicted in Table 2.

Variations of the exhaust gas recirculation (EGR) rate, of the combustion centre position MFB50\% (by adjusting the start of injection) and of the proportion of diesel fuel to alcoholic fuel (as percent energy share of the alcoholic fuel in relation to the total fuel energy, [\%e.]) were carried out. The pure diesel operation was the reference for the comparison. All specific emission values in this article are with respect to the indicated engine work. The results at OP-1500/5 may be seen as representative for OP-2000/5,
Table 2 Investigated operating points with engine parameters

\begin{tabular}{|c|c|c|c|c|c|}
\hline Operating point OP- & $1500 / 5$ & $1500 / 15$ & $2000 / 5^{\mathrm{a}}$ & $2000 / 20$ & $3000 / 20$ \\
\hline Speed [rpm] & 1500 & 1500 & 2000 & 2000 & 3000 \\
\hline IMEP [bar] & 5 & 15 & 5 & 20 & 20 \\
\hline Power output [kW] & 3.3 & 10 & 4.5 & 17.9 & 26.8 \\
\hline Rail pressure [bar] & $\sim 670$ & $\sim 1040$ & $\sim 800$ & $\sim 1240$ & $\sim 1400$ \\
\hline $\begin{array}{l}\text { Intake manifold } \\
\text { pressure (abs.) } \\
\text { [mbar] }\end{array}$ & 1130 & 2250 & 1230 & 2500 & 2600 \\
\hline $\begin{array}{l}\Delta \mathrm{p} \text { exhaust-intake } \\
{[\mathrm{mbar}]}\end{array}$ & 270 & 500 & 330 & 300 & 300 \\
\hline
\end{tabular}

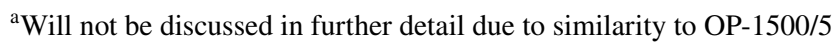

therefore OP-2000/5 will not be discussed in further detail in the following sections.

\subsection{Simulation model}

Besides the experimental investigations at the engine test bed, a 0D/1D-simulation model of the combustion process was additionally built and selected operating points were analysed with it. The software used was GT-POWER (v2016). An important feature of the simulation is the optional efficiency loss calculation, which contributes to the understanding of eventual efficiency differences between the discussed operating modes. The approach used for burn rate calculation was three pressure analysis (TPA) and required three measured pressure curves: intake, cylinder and exhaust. The test bed measurements delivered the input and calibration data for the simulation.

\section{Results of the combustion investigations}

At first, the effect of substituting diesel by an intake manifold injected alcoholic fuel is best demonstrated by increasing the substitution ratio. On the one hand, ethanol is characterized by a high octane number and low ignitability, therefore combustion may be retarded or incomplete, if pressure and temperature in the combustion chamber and/or ignition energy are not sufficient. On the other hand, since ethanol takes part at the combustion process in a premixed state and its ignition is externally induced, irregular combustion phenomena such as knock and pre-ignition are possible at high in-cylinder pressures and temperatures despite its high octane number. The high compression ratio of the diesel engine may promote knock within the alcoholic fuel charge due to higher compression peak temperature and pressure.

In the course of the investigations, at low load, degrading combustion quality, poor controllability and high cycle variation determined the maximum possible alternative fuel amount. In this project, a maximum substitution rate of 
60-70\% energy share was possible with the fuels used. At high loads it was the occurrence of knock and auto-ignition that prohibited further increase of the substitution ratio. Nevertheless, at OP-1500/15 still 50-60\%e. (\% energetic) substitution rate was achieved; the corresponding ranges for OP-2000/20 and OP-3000/20 were measured to be approximately $40 \%$ e. and $25 \%$ e., respectively. In accordance with its higher octane number, pure ethanol ensured slightly higher substitution rates at high load testing, whereas at OP-1500/5 it failed to provide stable combustion before E65 and E85 did.

\subsection{HC and CO pollutant emissions}

Compared to the diesel reference operation, the output of unburnt or partly burnt fuel was found to be considerable at dual-fuel mode, especially at low loads; Fig. 1. As can be seen in the graph for OP-1500/5, the amount of unburnt hydrocarbons (HC) and carbon monoxide (CO) steeply rose with the substitution rate. This severe disadvantage resulted in lower engine efficiency. The higher load points provided higher in-cylinder temperatures and pressures, hence ignition and combustion of the cylinder charge were much better supported and the incomplete combustion influence on engine efficiency diminished, Fig. 2. Experiments on a methanol fumigated diesel engine in [21] showed that the $\mathrm{HC}$ and $\mathrm{CO}$ emissions were also reduced with increase in intake air temperature.

\subsection{Efficiency and $\mathrm{CO}_{2}$ emissions}

Increasing the substitution rate at OP-1500/5 resulted in a considerable drop of engine efficiency until approximately $30 \%$ energy share and affected no significant further changes up to the maximum possible alcoholic fuel amount; Fig. 3. In contradiction to this case, a very pronounced efficiency

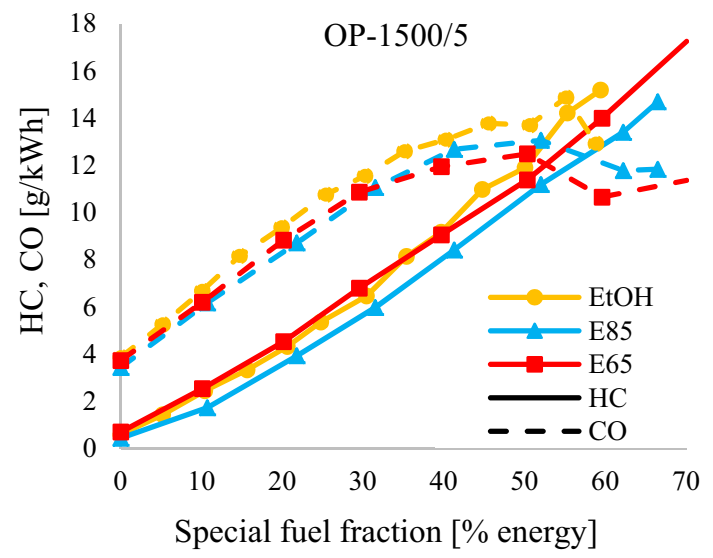

Fig. $1 \mathrm{HC}$ and $\mathrm{CO}$ emissions at OP-1500/5, 30\% EGR, $\mathrm{MFB} 50 \%=7.5^{\circ} \mathrm{CAaTDC}$

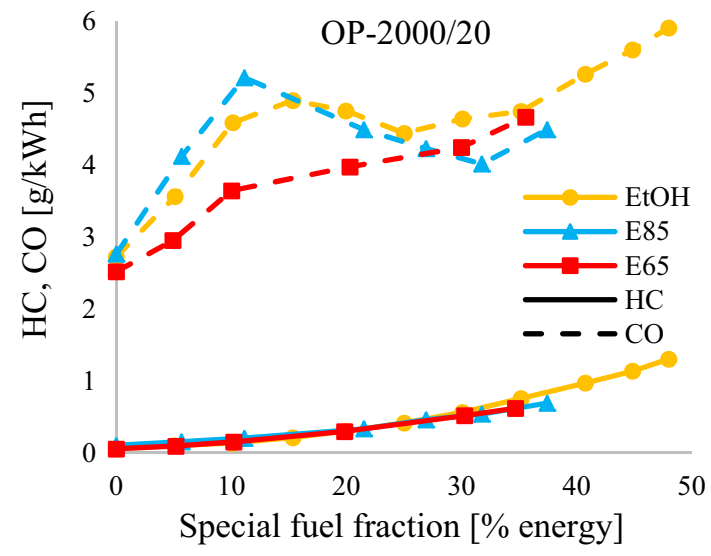

Fig. $2 \mathrm{HC}$ and $\mathrm{CO}$ emissions at OP-2000/20, 0\% EGR, $\mathrm{MFB} 50 \%=17.5^{\circ} \mathrm{CAaTDC}$

gain was measured at the medium and high load operating points, as can be seen in Figs. 3 and 4. Due to prolonged combustion duration and associated efficiency loss, the highest efficiency at "diesel only" operation was measured at an MFB50\% of $17.5^{\circ}$ CAaTDC for OP-2000/20 and at an MFB $50 \%$ of $20^{\circ}$ CAaTDC for OP-3000/20. Substituting diesel by an intake manifold injected alcoholic fuel at high load testing moved the highest efficiency combustion centre to more advanced MFB50\%, but, as could be expected, cylinder peak pressure, pressure rise rate and nitrogen oxide emissions were very high. Operating the engine in dual-fuel mode with high alcoholic fuel energy share not only impressively increased the engine efficiency, but also introduced a much higher tolerance against high EGR rates; Figs. 5 and 6. This benefit allowed the application of higher EGR rates without degrading the efficiency the same way as in pure diesel operation mode. In other words, a strong mechanism for mitigating the efficiency-NOx trade-off was introduced. In Fig. 6, the already mentioned additional engine efficiency

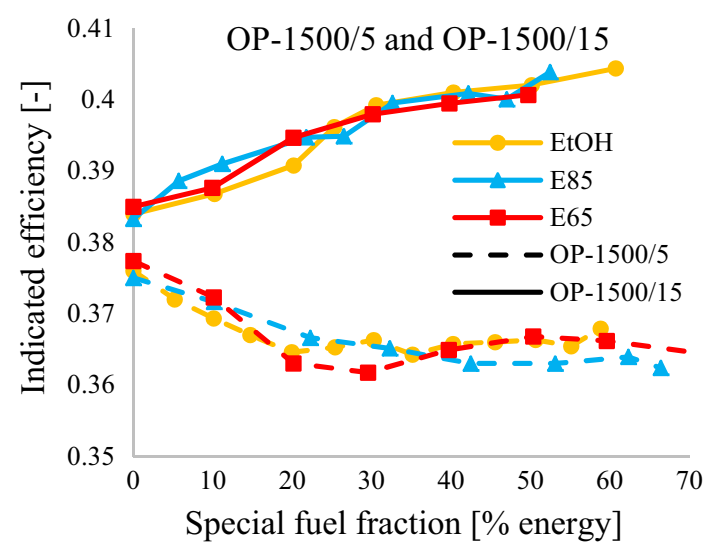

Fig. 3 Indicated efficiency at OP-1500/5 with 30\% EGR and OP- $1500 / 15$ with $15 \%$ EGR; MFB $50 \%=7.5^{\circ} \mathrm{CAaTDC}$ 


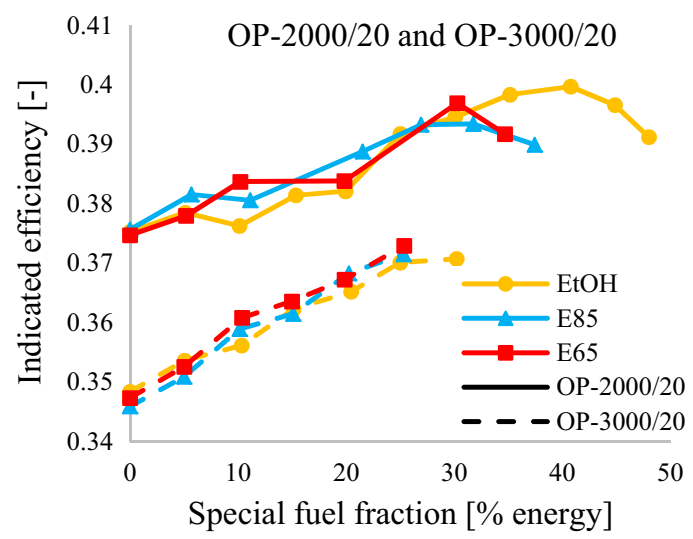

Fig. 4 Indicated efficiency at OP-2000/20 with MFB50\% $=17.5^{\circ}$ CAaTDC and OP-3000/20 with MFB50 $\%=20^{\circ}$ CAaTDC; 0\% EGR

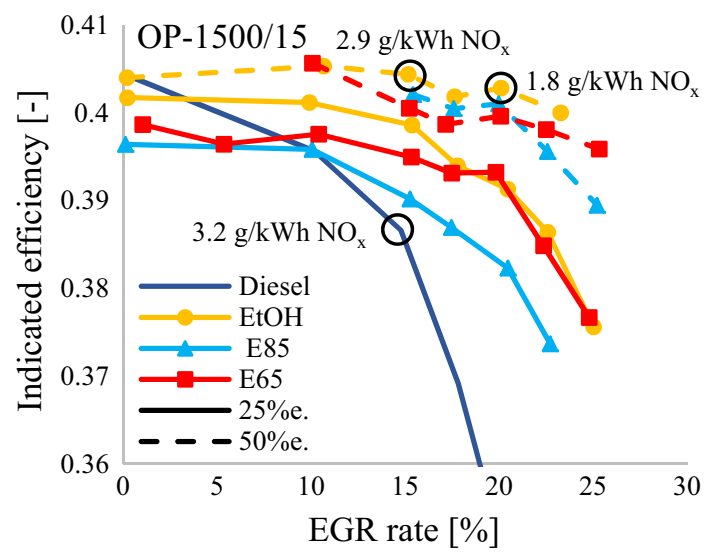

Fig. 5 Indicated efficiency at OP-1500/15, MFB50 $\%=7.5^{\circ} \mathrm{CAaTDC}$

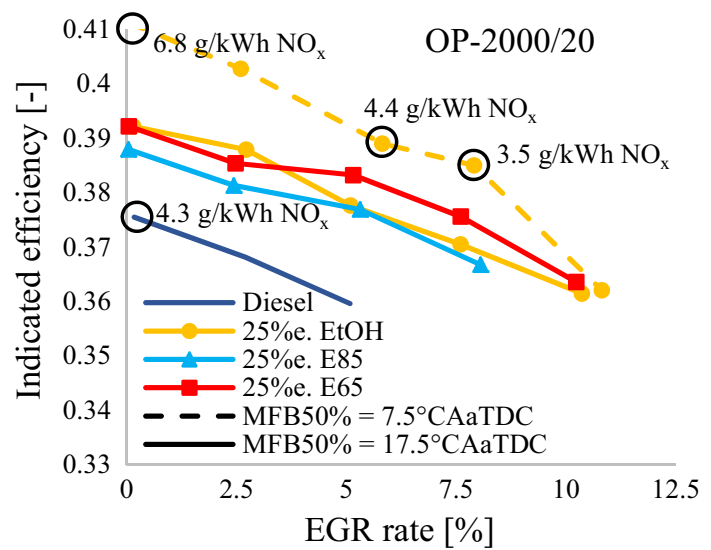

Fig. 6 Indicated efficiency at OP-2000/20

enhancement, which results from advancing MFB50\% when operating in dual-fuel mode at high loads, is shown together with the measured NOx values for some interesting points.

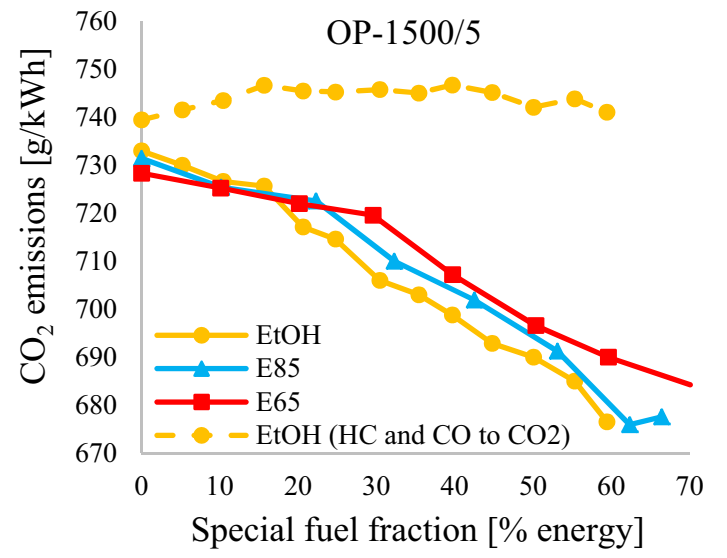

Fig. $7 \mathrm{CO}_{2}$ emissions at OP-1500/5, 30\% EGR, MFB50\% $=7.5^{\circ}$ CAaTDC

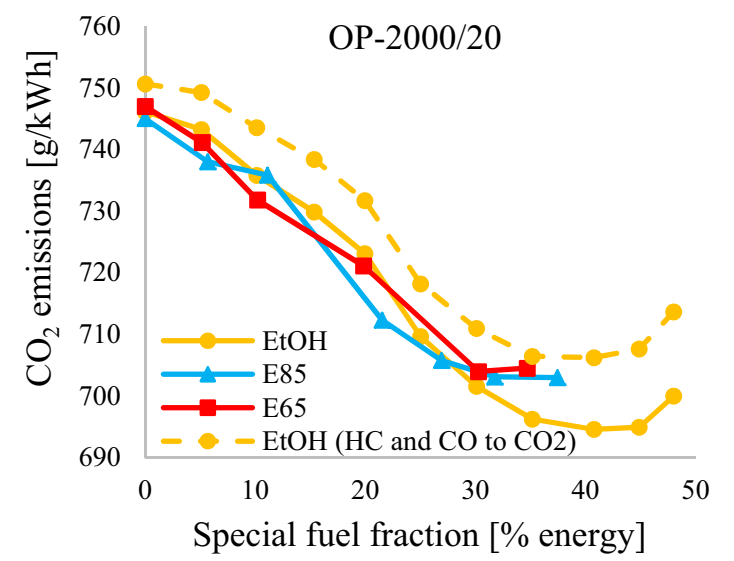

Fig. $8 \mathrm{CO}_{2}$ emissions at OP-2000/20, 0\% EGR, MFB50\% $=17.5^{\circ}$ CAaTDC

A remarkable reduction of the raw exhaust gas carbon dioxide emissions was measured with increase in substitution rate at all operating points, e.g. Figs. 7 and 8. Apart from OP-1500/5 (and OP-2000/5), the $\mathrm{CO}_{2}$ reduction reflects the efficiency increase at dual-fuel operation mode, which is illustrated by a comparison between Figs. 4 and 8. As will be proved later in this paper, the poor dual-fuel efficiency at OP-1500/5 is the consequence of high amounts of unburnt fuel, which do not react to $\mathrm{CO}_{2}$. At dual-fuel operation mode, the part of the fuel that gets ignited combusts thermodynamically more efficiently than diesel at "diesel only" operation; therefore, less energy input (= less fuel that ignites and burns) is needed to deliver the same engine power output and less $\mathrm{CO}_{2}$ is produced. The part of the fuel, which does not ignite and combust, is emitted as $\mathrm{HC}$ emissions and reduces the net engine efficiency. Additionally, the $\mathrm{CO}$ emissions increased with higher substitution rate. Unlike unburnt fuel (HC emissions), $\mathrm{CO}$ is a (incomplete) combustion product and its formation reduces the amount of the 
complete combustion product $\mathrm{CO}_{2}$. However, knowing this, the operation at load points with high $\mathrm{HC}$ and $\mathrm{CO}$ emissions cannot be rated as $\mathrm{CO}_{2}$ advantageous, since in a real-world application these pollutants would be converted to $\mathrm{CO}_{2}$ in an oxidation catalyst. For this reason, within a simplified approach the full conversion of $\mathrm{HC}$ and $\mathrm{CO}$ to $\mathrm{CO}_{2}$ was calculated for the case with pure ethanol operation following the presumption that all measured $\mathrm{HC}$ emissions in fact are unburnt ethanol molecules. The resulting $\mathrm{CO}_{2}$ emissions are added to the measured $\mathrm{CO}_{2}$ emissions in Figs. 7 and 8. As can be seen at low load operation with ethanol, the theoretical $\mathrm{CO}_{2}$ emissions are even slightly higher than in "diesel only". Nevertheless, at medium and high load operation with significantly less $\mathrm{HC}$ and $\mathrm{CO}$ pollutants, the $\mathrm{CO}_{2}$ savings are still considerable.

Summarizing these results, at high loads the indicated engine efficiency was significantly improved at dual-fuel operation mode with enhanced substitution ratios, whereas it dropped at low loads (similar results are also stated in [22]). The combustion process tolerance against high EGR rates allowed more exhaust gas to be recirculated without affecting engine efficiency the same way as at "diesel only" operation. Substituting diesel with manifold injected alcoholic fuels impressively reduced the engine $\mathrm{CO}_{2}$ emissions at medium and high load operating points.

\subsection{NOx, soot and particle emissions}

The results of the NOx and soot emissions measurements over the substitution rate for the tested operating points are depicted in Figs. 9 and 10. The soot mass in the exhaust gas was very effectively reduced at all operating points even when a relatively small diesel amount was replaced by ethanol, E85 or E65. The reduction, however, was at its strongest for approximately the first $20-30 \%$ of substituted

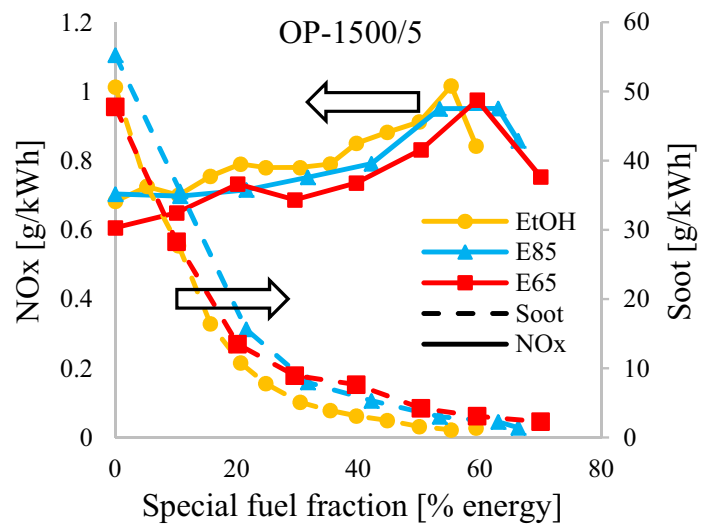

Fig. 9 NOx and soot emissions at OP-1500/5, 30\% EGR, $\mathrm{MFB} 50 \%=7.5^{\circ} \mathrm{CAaTDC}$

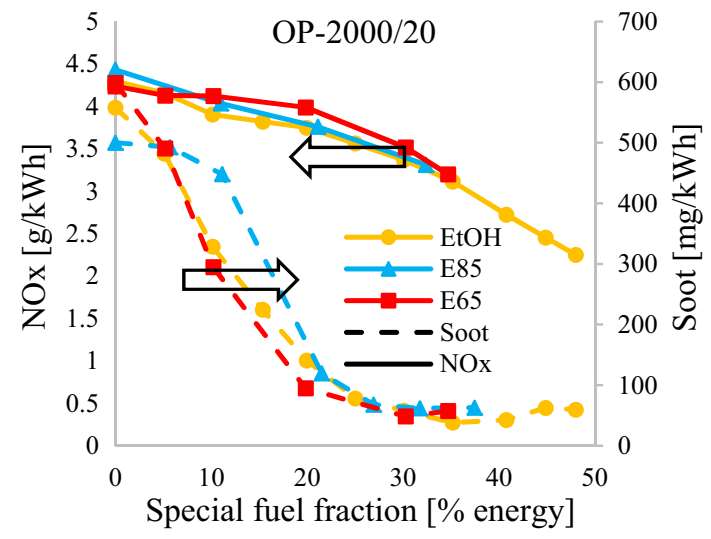

Fig. 10 NOx and soot emissions at OP-2000/20, 0\% EGR, $\mathrm{MFB} 50 \%=17.5^{\circ} \mathrm{CAaTDC}$

energy share. Afterwards, soot reduction continued only at a moderate rate or even stagnated.

Several factors play an important role in minimizing the soot emissions at dual-fuel operation. Ethanol per se is a substance, known for its almost soot-free combustion. The molecule contains only two carbon atoms, which are single bonded, the H/C ratio is higher than for many other fuels and the oxygen atom is available for the combustion directly within the reaction zone. Furthermore, the low boiling point of $78{ }^{\circ} \mathrm{C}$ promotes faster homogenization. Distinctive for the dual-fuel combustion process with external alcohol supply is the fact that enough time is available for the air-fuel mixture to be premixed and homogenized before the diesel jet induces the ignition. Thus, the locally fuel-rich zones are less and the formation of soot is limited. The lower aromatics amount also reduces the tendency to form soot precursors [23]. By replacing diesel, the appearance of diffusive diesel combustion is reduced and therefore less soot is produced. Ethanol has also a very high enthalpy of evaporation, which causes a strong cooling effect. With the cylinder charge temperature sinking, the injected diesel fuel needs more time to auto-ignite, its ignition delay is prolonged and more time remains available for diesel spray homogenization.

The behaviour of the NOx emissions over the substitution rate depends on the load conditions: at OP-1500/5 an increase was measured, while a strong reduction occurred at the tests with 20 bar IMEP. The most important factors for NOx formation are temperature, reactant availability and time. The extended ignition delay results in a faster and more compact combustion with higher heat release and higher peak temperatures. This aspect and the higher oxygen availability, which ethanol provides, increase the NOx production. The charge cooling effect of the ethanol evaporation decelerates the pollutant onset [22]. The combustion of the premixed mixture reduces the local peak temperatures, because the heat is released in the 
whole combustion chamber and not only in a small area around the diesel jet. Higher thermodynamic combustion efficiency means that less fuel is burnt and therefore less heat is released, which also may lower the NOx output. Additionally, ethanol burns with a lower flame temperature than diesel due to the composition of the combustion products [7, 24]. Whether the NOx emissions rise or sink when substituting diesel through manifold injected alcoholic fuel depends on the weight and occurrence of the factors listed above.

As can be seen in an earlier publication on this topic [8], with higher substitution rate the ratio $\mathrm{NO}_{2} / \mathrm{NO}$ got higher, because less $\mathrm{NO}$ and more $\mathrm{NO}_{2}$ were produced compared to "diesel only" operation. The sinking in-cylinder charge temperature due to the alcohol's higher heat of evaporation surely may contribute to this phenomenon [21], the main reason, however, is believed to be the presence of free hydroperoxyl radicals $\mathrm{HO}_{2}$, which are delivered within alcohol combustion [16, 21, 25].

Together with the soot mass, the particle number also dropped, as diesel was replaced by the alternative fuel. By mitigating the smoke problem of the diesel engine, more EGR could be used as an in-cylinder measure for further NOx emission reduction-the diesel typical soot-NOx trade-off was weakened. Figures 11 and 12 illustrate the particle-NOx trade-off for low and medium load and different substitution rates. An outstanding advantage is visible for dual-fuel operation mode, in particular for OP-1500/5.

In $[16,23,26]$, the chemicophysical features of the soot emitted from a dual-fuel ethanol-diesel system are investigated and it is reported that the results indicate a significant effect of ethanol on the particle number, but not on the average size. Furthermore, the impact of the ethanol-premixed charge on the soot nanostructural features is found to be negligible.

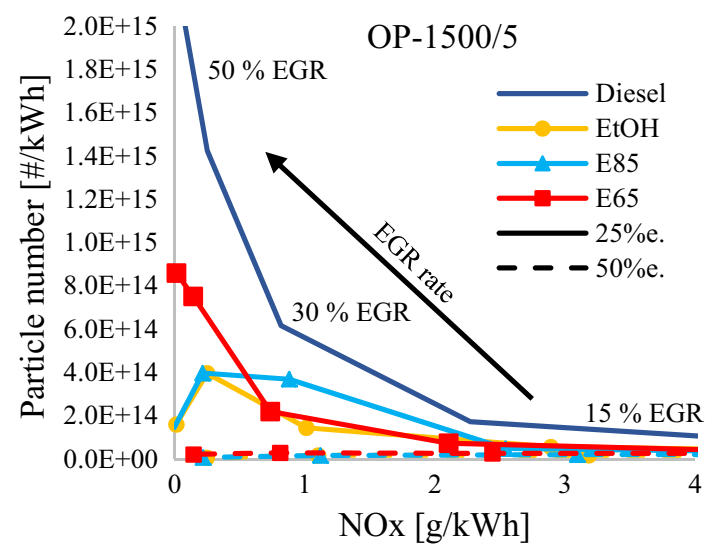

Fig. 11 Particle number-NOx trade-off at OP-1500/5, $\mathrm{MFB} 50 \%=7.5^{\circ} \mathrm{CAaTDC}$

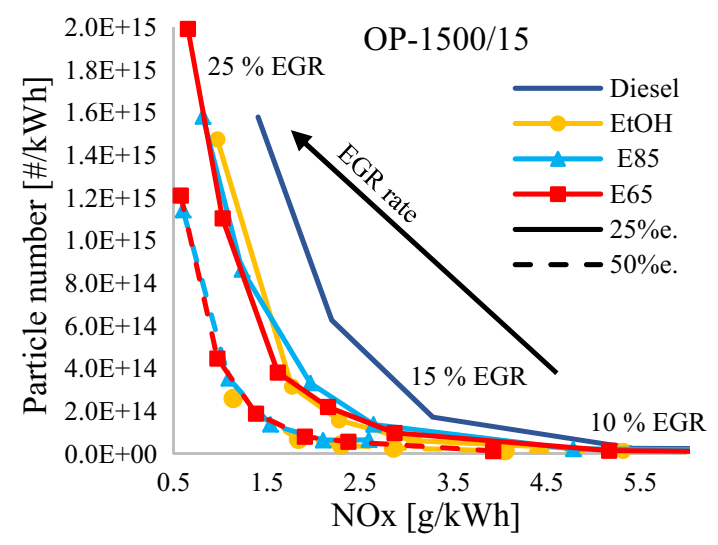

Fig. 12 Particle number-NOx trade-off at OP-1500/15, $\mathrm{MFB} 50 \%=7.5^{\circ} \mathrm{CAaTDC}$

\subsection{Combustion analysis}

The analysis of the indicated data generally showed that at dual-fuel mode, the combustion process is characterized by a shorter burning duration; Figs. 13 and Fig. 14. At low load in dual-fuel mode, more time was needed for combustion to start and the diesel injection had to be advanced. Compared to diesel reference operation, at medium and higher load, the ignition delay in dual-fuel mode was shortened and the same MFB50\% was set by a retarded injection timing. After ignition occurred, the main combustion phase was completed faster than at "diesel only" operation. The postcombustion phase, which is distinctive for the oxidation of the soot formed during the diesel main combustion phase, was in most cases shorter and with a lower heat release. From an efficiency point of view, all this aspects lead to a thermodynamic beneficial cylinder pressure curve shaping. Their precise value is tightly dependent on load point, EGR,

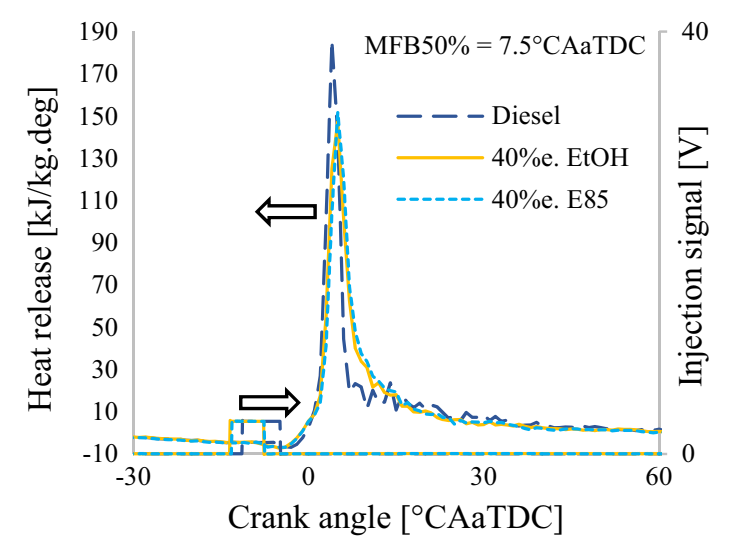

Fig. 13 Indicated heat release rate at OP-1500/5, 30\% EGR, $\mathrm{MFB} 50 \%=7.5^{\circ} \mathrm{CAaTDC}$ 


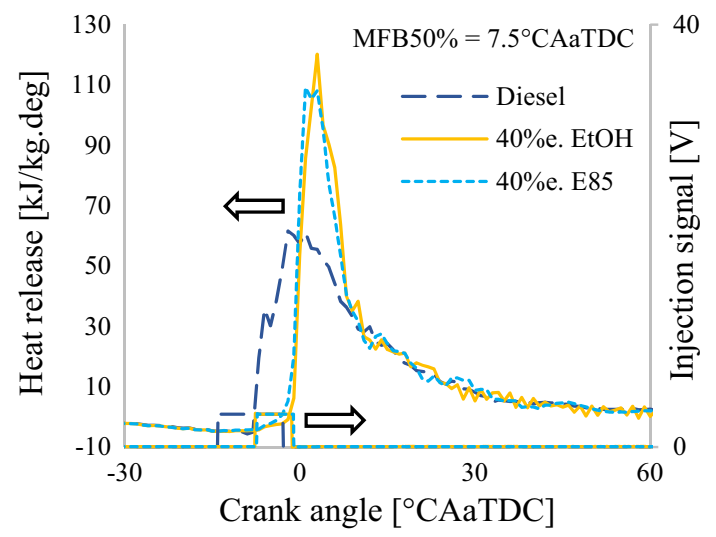

Fig. 14 Indicated heat release rate at OP-1500/15, 15\% EGR, $\mathrm{MFB} 50 \%=7.5^{\circ} \mathrm{CAaTDC}$

manifold pressure, MFB50\%, engine speed and, of course, fuel.

Besides the above-mentioned, at some conditions a very important combustion phenomenon was detected-a cyclic reproducible auto-ignition of the premixed homogenous charge. For internal combustion engines, there are three major combustion processes [27]: (1) spark ignition (SI) with premixed flame propagation, (2) compression ignition (CI) with non-premixed (diffusion) flame and (3) homogeneous charge compression ignition (HCCI) with bulk auto-ignition of a premixed charge. If the diesel amount in dual-fuel mode was only as much as it is needed to initiate mixture ignition, the process could be seen as similar to (1).

With the fuel fractions used in the current project, however, the process was somewhere between (1) and (2): a compression ignition of the diesel fuel and a subsequent ignition and a flame propagation of the premixed (air/ ethanol) charge. With pre-ignition occurring, the process becomes a mix of (3) and (2). If all of the ethanol does not auto-ignite, a part of it has to burn deflagratively, so the whole combustion process represents a combination of (1), (2) and (3).

Figure 15 shows the heat release in diesel reference operation and dual-fuel operation mode with $30 \%$ energy share of ethanol or E85 at OP-2000/20, MFB50\% was at $17.5^{\circ}$ CAaTDC. As can be seen, the combustion in the case of ethanol clearly begins before the start of the diesel injection. After a rapid and intensive heat release, the main combustion of the injected diesel continues at a moderate rate. With E85 (and E65), the combustion starts even earlier and the heat release of the premixed stage is remarkably higher. According to the octane number of the fuels, E85 is more reactive and ignites easier than ethanol. The described auto-ignition of the premixed charge was not accidental, but permanent and stable in every cycle. It appeared with late MFB50\% at medium and high load and was more distinct at

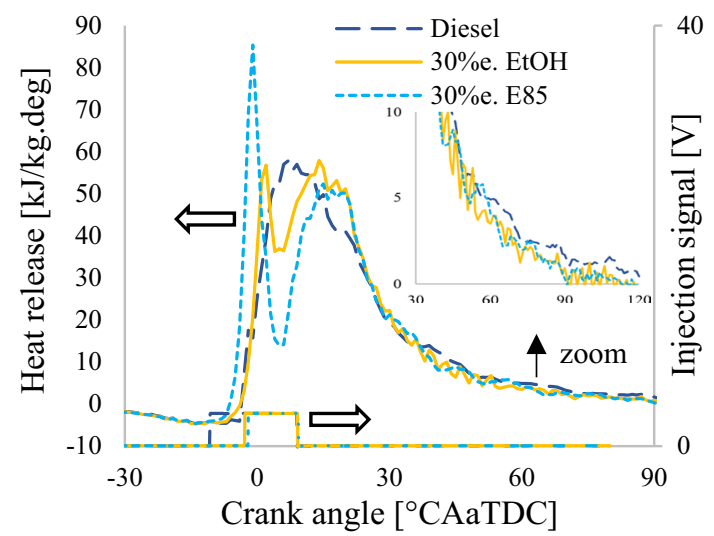

Fig. 15 Indicated heat release rate at OP-2000/20, 0\% EGR, MFB $50 \%=17.5^{\circ} \mathrm{CAaTDC}$

low speeds. As could be expected, it emitted more noise, but the cylinder peak pressure was only inconsiderably higher than in the diesel reference operation (approx. 150 bar). The experiments proved that the auto-ignition was existent even after the diesel supply had been completely turned off. Figure 16 shows the same operating point, but with an advanced MFB50\% of $7.5^{\circ}$ CAaTDC. This combustion centre position was much too early for diesel reference operation and resulted in an efficiency decrease due to a disadvantageous heat release timing. As can be seen in the graph, in the case of "diesel only", a lot of energy is released long before the piston reaches the top dead centre, thus high blow-by and wall heat losses occur.

Since dual-fuel operation provided a much faster combustion, engine efficiency was even impressively increased at an MFB50\% of $7.5^{\circ}$ CAaTDC; see Fig. 6. Cylinder peak pressure was, however, in the range of $200 \mathrm{bar}$ and the energy fraction of the alcoholic fuel had to be lowered to $25 \%$ e. to prevent mechanical damage. The maximum

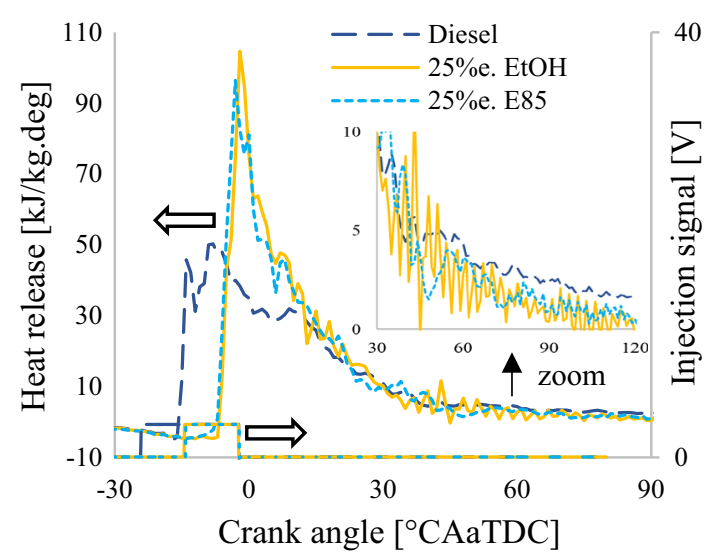

Fig. 16 Indicated heat release at OP-2000/20, 0\% EGR, $\mathrm{MFB} 50 \%=7.5^{\circ} \mathrm{CAaTDC}$ 
pressure rise rate with $25 \% \mathrm{e}$. ethanol was $8.5 \mathrm{bar} /{ }^{\circ} \mathrm{C}$ A at an MFB50\% of $17.5^{\circ} \mathrm{CAaTDC}$ and $18 \mathrm{bar} /{ }^{\circ} \mathrm{CA}$ at an MFB50\% of $7.5^{\circ} \mathrm{CAaTDC}$. For demonstration purpose, tests with $40 \%$ e. were also conducted and the maximum pressure rise rate reached $26 \mathrm{bar} /{ }^{\circ} \mathrm{CA}$ at an MFB50\% of $7.5^{\circ} \mathrm{CAaTDC}$ (these results are not illustrated here). Compared to Fig. 15, advancing MFB50\% in Fig. 16 demands a much earlier start of injection and the diesel combustion starts before the theoretical start of the ethanol auto-ignition, so no pre-ignition is detected. In both cases shown above, the pure diesel operation features a higher heat release in the post-oxidation phase than dual-fuel operation.

According to the findings of the literature survey, the combustion process in dual-fuel mode may be designed to fit different concepts, e.g. [17, 18]. The occurrence of knock and auto-ignition as well as the feasibility of different combustion concepts depend mainly on the properties of the fuel. Auto-ignition and knock can be supressed or controlled by optimizing the ethanol energy fraction, the EGR rate, the global air/fuel equivalence ratio, the intake air temperature and the compression ratio. The correct adjustment of these parameters can extend the engine's operating region and diesel substitution rates [28].

\section{Simulation results and efficiency loss analysis}

\subsection{Simulation results}

The quality of the $0 \mathrm{D} / 1 \mathrm{D}$ single-cylinder simulation model was verified by a comparison with the experimental data, both indicated and conventional. Calculated power output, airflow, fuel consumption and engine efficiency closely matched the test values at all operating points. The original purpose of the simulation was to explain the engine efficiency differences visible in Figs. 3, 4, 5 and 6 in a quantitative manner. Some important simulation results are selected and discussed here. The findings are based on OP-2000/20.

The attempt to simply determine the cylinder temperature as a result of the indicated pressure and cylinder geometry by using a common post-processing software tool was found to be inappropriate, since the presence of a second fuel changes the composition and consequently the thermodynamic properties of the cylinder charge. The chosen simulation package considers these factors, and the calculated $\mathrm{O}_{2}, \mathrm{CO}_{2}$ and $\mathrm{H}_{2} \mathrm{O}$ mass fractions are shown in Fig. 17.

It can be seen that "diesel only" combustion requires more oxygen, mainly due to the lower process efficiency at this setting. In dual-fuel mode, the $\mathrm{CO}_{2}$ fraction is lower and that of water is higher. This distribution suggests less charge-related efficiency losses, because the heat capacity ratio of water is higher than of $\mathrm{CO}_{2}$-at $1273 \mathrm{~K}$ the values

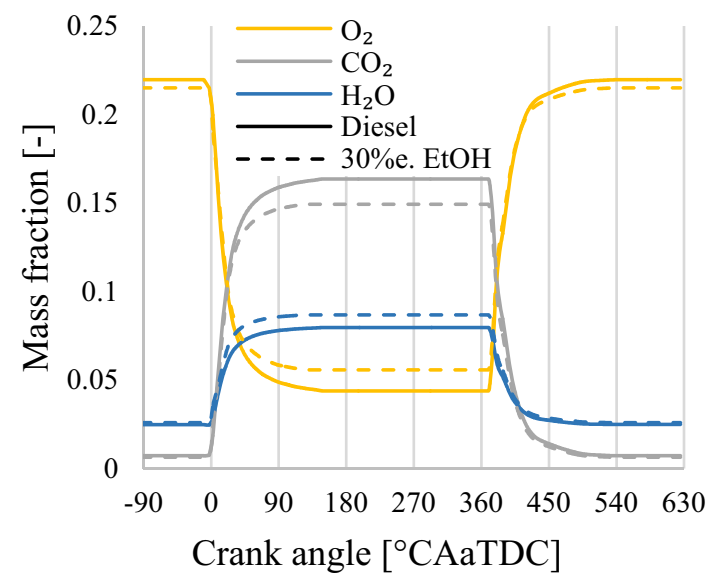

Fig. 17 Simulated combustion cycle $\mathrm{O}_{2}, \mathrm{CO}_{2}$ and $\mathrm{H}_{2} \mathrm{O}$ mass fractions at OP-2000/20, 0\% EGR, MFB50 $\%=17.5^{\circ}$ CAaTDC. Comparison between "diesel only" operation and dual-fuel operation with $30 \%$ ethanol energy share

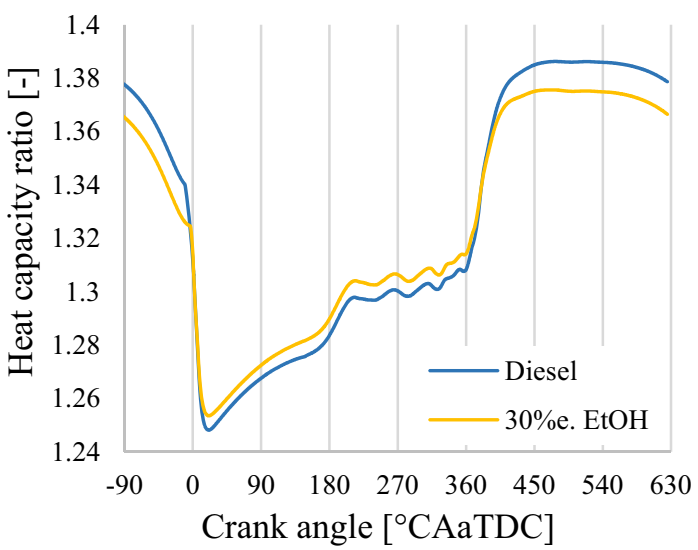

Fig. 18 Simulated heat capacity ratio $c_{\mathrm{p}} / c_{\mathrm{v}}$ at OP-2000/20, 0\% EGR, MFB50 $\%=17.5^{\circ}$ CAaTDC. Comparison between "diesel only" operation and dual-fuel operation with $30 \%$ ethanol energy share

are as follows: $\mathrm{O}_{2} 1.302 ; \mathrm{CO}_{2} 1.172 ; \mathrm{H}_{2} \mathrm{O}$ 1.23. Figure 18 confirms this assumption for the working cycle. Engine efficiency gains as a result of reduced losses due to real charge composition and real fluid properties are expected according to this finding. During the compression stroke, $c_{\mathrm{p} /} c_{\mathrm{v}}$ is lower in dual-fuel mode because a mixture of ethanol and air has a lower heat capacity ratio than pure air.

With the known variables cylinder pressure and charge composition, the cylinder average temperature can be calculated. As can be seen in Fig. 19, the cylinder temperature in dual-fuel operation with $30 \%$ ethanol energy share is lower than in "diesel only" operation throughout the whole cycle (except for the short range after TDC). The simulated heat flux from the fluid to the walls is shown in Fig. 20. In the range of 0 to $7^{\circ} \mathrm{CAaTDC}$, a marginally higher heat transfer occurs when operating with $30 \%$ e. 


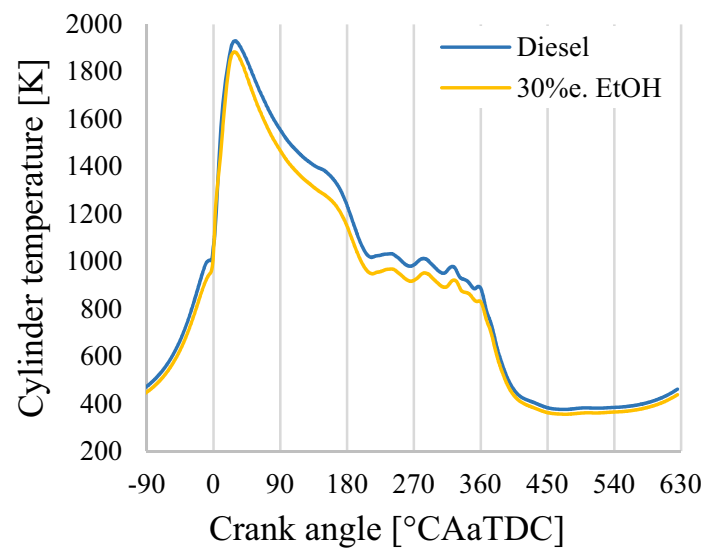

Fig. 19 Simulated cylinder temperature at OP-2000/20, 0\% EGR, $\mathrm{MFB} 50 \%=17.5^{\circ} \mathrm{CAaTDC}$. Comparison between "diesel only" operation and dual-fuel operation with $30 \%$ ethanol energy share

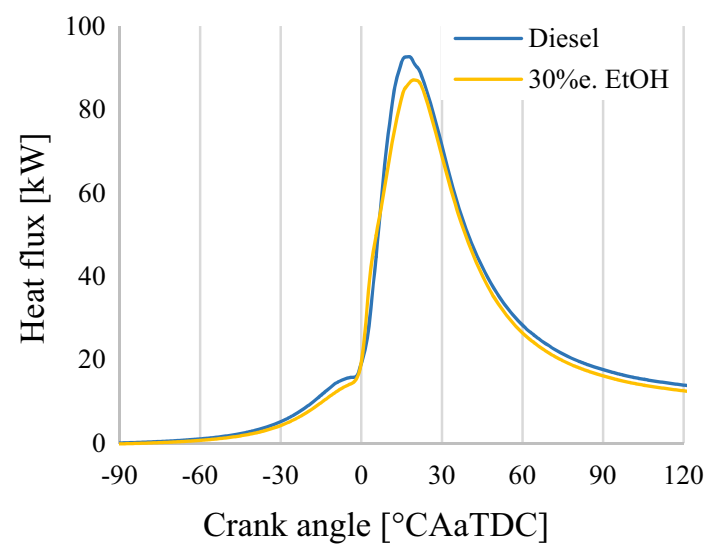

Fig. 20 Simulated heat flux from fluid to wall at OP-2000/20, 0\% EGR, MFB50\% $=17.5^{\circ}$ CAaTDC. Comparison between "diesel only" operation and dual-fuel operation with $30 \%$ ethanol energy share ethanol, apart from that the heat flux in dual-fuel mode is lower.

\subsection{Efficiency loss analysis}

An efficiency loss analysis is shown in Fig. 21 for low, medium and high load operation. In agreement with the engine test bed findings, compared to the diesel reference operation, the indicated efficiency in dual-fuel mode is reduced only at the 5 bar indicated mean effective pressure load point. The bar chart clearly visualizes the source of the major efficiency loss-a high percentage of incomplete combustion, as it was presumed in Fig. 1. At the other investigated load points, a higher share of incomplete combustion is also encountered in dual-fuel mode, it is however significantly lower than at OP-1500/5 and is being overcompensated by a series of efficiency gains.

Due to the changed fluid composition, the real charge and real fluid properties losses sink at all dual-fuel operating points. Since MFB50\% was held approximately equal for each pair "diesel only-dual-fuel", the loss due to combustion phasing is also basically identical. In a similar way, the constant pressure difference "exhaust - manifold" was set to exclude the gas exchange influence on the combustion process efficiency. The "real burn rate" shares in the diagram prove the accelerated combustion at dual-fuel mode to be one of the main reasons for higher efficiency.

Another loss that is generally reduced when operating with intake manifold alcoholic fuel injection is the wall heat transfer. Surprisingly, despite the evidence in Fig. 20, the calculated heat transfer loss at OP-2000/20 is equal for both combustion processes. The efficiency loss is calculated by relating the specific particular work loss to the work that would result from the brought-in fuel energy with no losses at all (100\% efficiency). The software calculated 2.6 bar mean effective pressure loss due to heat transfer for the "diesel only" case and 2.5 bar for the dual-fuel case with $30 \%$
Fig. 21 Results of the efficiency loss analysis for three operation points. Comparison between "diesel only" operation mode and dual-fuel operation

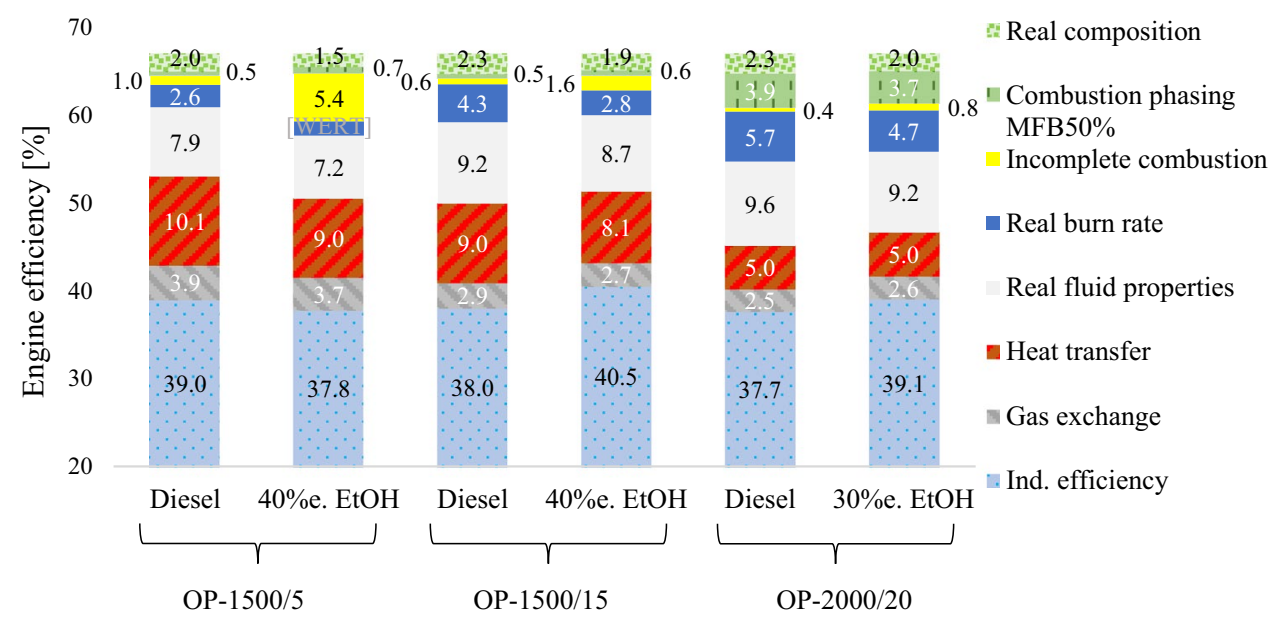


ethanol energy share, so both cases differ by only 0.1 bar. However, dual-fuel mode operation also requires less fuel energy than diesel reference operation $(2.73 \mathrm{vs} 2.85 \mathrm{~kJ} /$ cycle), so the percentage heat loss share in this case is barely changed. At OP-1500/15 for example, the mean effective pressure lost due to wall heat losses in "diesel only" operation is 3.58 bar and 3 bar in dual-fuel mode, whereas the fuel energy in the first case is 2.13 and $2 \mathrm{~kJ} /$ cycle in the second. These values lead to a significantly reduced heat transfer loss in dual-fuel mode.

It should be noted that the calculated values for wall heat transfer have to be interpreted with care when comparing stratified operation (as in pure diesel mode) and partially premixed operation (as in dual-fuel mode), as the used wall heat transfer model in the 0-dimensional approach (Woschni Classic) does not account for stratification effects. Therefore, wall heat loss for stratified operation tends to be overestimated in comparison to homogenous (or partly homogenous) operation.

\section{Conclusions}

The usage of ethanol and two different mixtures of ethanol and gasoline (E85 and E65) was investigated on a modified diesel engine designed to work in a dual-fuel combustion mode with intake manifold alcohol injection. The maximum ratio of alcohol to diesel fuel was limited by irregular combustion phenomena like degrading combustion quality and poor process controllability at low load and knock as well as auto-ignition at high load. At low load testing, up to $70 \%$ of the diesel energy could be substituted by the alcoholic fuels, whereas at high loads the maximum substitution rate declined to $30 \%$ e. With rising alcohol amount, a significant reduction of soot mass and particle number of up to 99\% (depending on load point and substitution ratio) was observed. At some testing points, substituting diesel with ethanol, E65 or E85 led to a reduction of NOx emissions; however, the real benefit concerning the nitrogen oxides was introduced by the mitigation of the soot-NOx trade-off. The low soot emissions in dual-fuel operation mode allowed a further increase of the EGR rate, which helped lower the NOx emissions far below the diesel reference operation values. The indicated engine efficiency was significantly improved with enhanced substitution ratios at medium and high loads (by up to 6\%), whereas it dropped at low loads (by approx. 3\%). The combustion process tolerance against high EGR rates in dual-fuel mode allowed more exhaust gas to be recirculated without affecting engine efficiency the same way as in "diesel only" operation. Substituting diesel with manifold injected alcoholic fuels impressively reduced the engine $\mathrm{CO}_{2}$ emissions at medium and high load operating points. The catalytic conversion of the high $\mathrm{HC}$ and $\mathrm{CO}$ emissions measured at low load operation would eventually lead to higher tailpipe $\mathrm{CO}_{2}$ emissions.

The analysis of the indicated data generally showed that at dual-fuel mode, the combustion process is characterized by a shorter burning duration. At low load, more time was needed for combustion to start at dual-fuel mode. Compared to diesel reference operation, at medium and higher load, the ignition delay was shortened. At some conditions and higher loads, a cyclic reproducible auto-ignition of the premixed homogenous charge occurred.

A simulation model was built for the test engine and selected operating points from the engine test bed measurements were implemented into the model to generate an efficiency loss analysis. The calculations showed that the high amounts of unburnt fuel at dual-fuel operation were the main reason for efficiency degradation, whereas the reduced losses due to real charge composition, real fluid properties, real burn rate and heat transfer enhanced the efficiency of the engine at dual-fuel mode.

Acknowledgements Open access funding provided by TU Wien (TUW). The authors would like to thank AGRANA Beteiligungs-AG, Austria's biggest bio-ethanol producer, for supporting this project.

Open Access This article is distributed under the terms of the Creative Commons Attribution 4.0 International License (http://creativeco mmons.org/licenses/by/4.0/), which permits unrestricted use, distribution, and reproduction in any medium, provided you give appropriate credit to the original author(s) and the source, provide a link to the Creative Commons license, and indicate if changes were made.

\section{References}

1. Eurostat: Greenhouse gas emission statistics. http://ec.europa.eu/ eurostat/statistics-explained/index.php/Greenhouse_gas_emiss ion_statistics. Accessed 7 Nov 2018

2. Kumar, A., Ogita, S., Yau, Y.: Biofuels: Greenhouse Gas Mitigation and Global Warming. Next Generation Biofuels and Role of Biotechnology. Springer, New York (2018). https://doi. org/10.1007/978-81-322-3763-1 (ISBN 978-81-322-3761-7)

3. Gangl, Ch: Ethanolerzeugung aus stärkehaltigen Rohstoffen für Treibstoffzwecke; master thesis; University of Natural Resources and Life Sciences, Vienna (BOKU); September (2004)

4. Scheper, T., Olssen, L.: Biofuels: Part of the Advances in Biochemical Engineering/Biotechnology Book Series (ABE), vol. 108. Springer, New York (2007). https://doi.org/10.1007/9783-540-73651-6 (ISBN 978-3-540-73650-9)

5. Paschalidou, A., Tsatiris, M., Kitikidou, K., Papadopoulou, C.: Using Energy Crops for Biofuels or Food: The Choice. Springer, New York (2018) https://doi.org/10.1007/978-3-319-63943-7 (ISBN 978-3-319-63942-0)

6. HLPE: Biofuels and food security. A report by the High Level Panel of Experts on Food Security and Nutrition of the Committee on World Food Security, Rome (2013)

7. Iverfeldt, E., Stalhammar, P., Sarby, H., Ihrfors, C., Westman, B.: Sustainable Transportation by Using Ethanol in Diesel Engines; 
Lenz (Hrsg). 36th International Vienna Motor Symposium (2015), 7-8 May 2015, Vienna (ISBN 978-3-18-378312-0)

8. Damyanov, A., Hofmann, P., Derntl, M., Schüßler, M., Pichler, T., Schwaiger, N.: Operation of a diesel engine with biogenous oxygenated fuels; Lenz (Hrsg.). 38th International Vienna Motor Symposium (2017), 27-28 April 2017, Vienna (ISBN 978-3-18-380212-8)

9. Karim, G.A.: Dual-Fuel Diesel Engines. CRC Press Taylor \& Francis Group, Boca Raton, 2015 (ISBN 978-1-4987-0308-6)

10. Sprenger, F., Fasching, P., Eichlseder, H.: Erdgas-diesel dualdirect-injection-Ein alternatives Brennverfahren zur signifikanten $\mathrm{CO}_{2}$-Reduzierung. In: Tschöke, H., Marohn, R. (eds.) Proceedings, 10. Tagung Diesel-und Benzindirekteinspritzung (2016), 24-25 November 2016, Berlin. https://doi. org/10.1007/978-3-658-15327-4_22

11. Lee, J., Chu, S., Kang, J., Min, K., Jung, H., Kim, H., Chi, Y.: Operating strategy for gasoline/diesel dual-fuel premixed compression ignition in a light-duty diesel engine. Int. J. Automot. Technol. (2017). https://doi.org/10.1007/s12239-017-0092-7

12. Damyanov, A., Hofmann, P., Derntl, M., Schüßler, M., Pichler, T., Schwaiger, N., Siebenhofer, M.: Regenerative oxygen-containing diesel substitute fuels as an ecological option for increasing efficiency and minimizing emissions. In: Nikolai Schubert (ed.) Proceedings of the 11th International Colloquium Fuels, Ostfildern, Juni 27-29, 2017

13. Lau, C.S.: Biogas upgrade through exhaust gas reforming process for use in CI engines; Dissertation, University of Birmingham (2012)

14. Theinnoi, K., Suksompong, P., Temwutthikun, W.: Engine performance of dual fuel operation with in-cylinder injected diesel fuels and in-port injected DME. In: 9th International Conference on Applied Energy, ICAE2017, 21-24 August 2017, Cardiff, UK. https://doi.org/10.1016/j.egypro.2017.12.072

15. Diesel, R.: Method of igniting and regulating combustion for internal combustion engines. US Patent 673160, April (1901)

16. Zhang, Z.H., Tsang, K.S., Cheung, C.S., Chan, T.L., Yao, C.D.: Effect of fumigation methanol and ethanol on the gaseous and particulate emissions of a direct injection diesel engine. Atmos. Environ. (2011). https://doi.org/10.1016/j.atmosenv.2010.12.019

17. Ogawa, H., Shibata, G., Kato, T., Zhao, P.: Dual fuel diesel combustion with premixed ethanol as the main fuel. SAE Technical Paper 2014-01-2687 (2014). https://doi. org/10.4271/2014-01-2678

18. Heuser, B., Kremer, F., Pischinger, S.: An experimental investigation of dual-fuel combustion in a light duty diesel engine by in-cylinder blending of ethanol and diesel. SAE Int. J. Eng. (2016). https://doi.org/10.4271/2015-01-1801

19. Niskanen, H.: Alkoholbetriebene Traktoren; Oldtimertrecker.de. https://www.oldtimertrecker.de/alkoholbetriebene-traktoren-inbrasilien/. Accessed 8 Nov 2018

20. Imran, A., Varman, M., Masjuki, H.H., Kalam, M.A.: Review on alcohol fumigation on diesel engine: a viable alternative dual fuel technology for satisfactory engine performance and reduction of environment concerning emission. Renew. Sustain. Energy Rev. (2013). https://doi.org/10.1016/j.rser.2013.05.070

21. Pan, W., Yao, C., Han, G., Wei, H., Wang, Q.: The impact of intake air temperature on performance and exhaust emissions of a diesel methanol dual fuel engine. Fuel (2015). https://doi. org/10.1016/j.fuel.2015.08.073

22. Masimalai, S.K.: Influence of methanol induction on performance, emission and combustion behavior of a methanol-diesel dual fuel engine. SAE Technical Paper 2014-01-1315 (2014). https:// doi.org/10.4271/2014-01-1315

23. Gargiulo, V., Alfe, M., Blasio, G.D., Beatrice, C.: Chemicophysical features of soot emitted from a dual-fuel ethanol-diesel system. Fuel (2015). https://doi.org/10.1016/j.fuel.2015.01.096

24. Glaude, P.-A., Fournet, R., Bounaceur, R., Moliere, M.: Adiabatic flame temperature from biofuels and fossil fuels and derived effect on NOx emissions. Fuel Process. Technol. (2010). https:// doi.org/10.1016/j.fuproc.2009.10.002

25. Warnatz, J., Maas, U., Dibble, R.W.: Combustion. Physical and Chemical Fundamentals, Modeling and Simulation, Experiments, Pollutant Formation, 4th Edn. Springer, New York (2006) (ISBN13 978-3-540-25992-3\$4)

26. Zhang, Z.H., Cheung, C.S., Chan, T.L., Yao, C.D.: Emission reduction from diesel engine using fumigation methanol and diesel oxidation catalyst; Sci. Total Environ. (2009). https://doi. org/10.1016/j.scitotenv.2009.04.036

27. Boot, M.: Biofuels from Lignocellulosic Biomass. Innovations beyond Bioethanol. Wiley-VCH Verlag GmbH \& Co., New York (2016) (ISBN: 978-3-527-33813-9)

28. Pedrozo, V.B., Zhao, H.: Improvement in high load ethanol-diesel dual-fuel combustion by Miller cycle and charge air cooling. Appl. Energy (2018). https://doi.org/10.1016/j.apenergy.2017.10.092

Publisher's Note Springer Nature remains neutral with regard to jurisdictional claims in published maps and institutional affiliations. 